\title{
Shoah y Spielberg: \\ 25 años de un modelo narrativo para contar el Holocausto
}

\author{
Carlos López-Olano \\ Juan Carlos Colomer Rubio
}

Recibido: 07.07.2020 — Aceptado: 28.07.2020

\section{Titre / Title / Titolo}

Shoah et Spielberg. Un model narratif pour raconter l'Holocaust, 25 ans après Shoah and Spielberg. A Narrative Model to Tell the Holocaust, 25 Years Later Shoah e Spielberg. Un modelo nattarivo per raccontare l'Olocausto, 25 anni dopo

\section{Resumen / Résumé / Abstract/ Riassunto}

La lista de Schindler representó un punto de inflexión en la narrativa sobre el Holocausto. A pesar de que fue bien recibida por crítica y público, algo nada habitual en la trayectoria de un Steven Spielberg al que se tildaba de autor infantil y bueno sólo como realizador de cine de aventuras, la película no lo fue tanto en los círculos intelectuales judíos. La crítica negativa a la fábula cruel pero esperanzada de Spielberg fue ejercida especialmente por el director de otra de las propuestas cinematográficas que desde el extremo opuesto formalmente, también sentó referencia en el género: Claude Lanzmann y su monumental Shoah. Ahora, un cuarto de siglo después, queremos analizar en este artículo que queda sobre la discusión y el modelo narrativo impuesto por Spielberg cuando se trata de recordar uno de los episodios más negros de la historia reciente: el intento de exterminio nazi de los judíos.

La liste de Schindler représente un tournant dans le récit de l'Holocauste. Bien qu'il ait été bien accueilli par la critique et le public, quelque chose d'inhabituel dans la carrière de Steven Spielberg, accusé d'être un auteur pour enfants et assez bon uniquement en tant que cinéaste d'aventures, le film n'a pas été tellement accepté par les intellectuels juifs. La critique négative de la fable cruelle mais pleine d'espoir de Spielberg a été exercée surtout par le réalisateur d'une autre référence du genre, mais formellement de l'extrême opposé: Claude Lanzmann et sa monumentale Shoah. Maintenant, un quart de siècle plus tard, nous voulons analyser dans cet article ce qui reste de la discussion et du modèle de Spielberg sur la narration de l'un des épisodes les plus noirs de l'histoire récente: la tentative nazie d'extermination des juifs.
Schindler's list represents a turning point in the narrative of the Holocaust. The film was well received by critics and the public, something unusual in Steven Spielberg's career, as he was often considered as an author for children and good enough only as a filmmaker of adventures, yet not so much in Jewish intellectual circles. The negative critique to Spielberg's cruel but hopeful fable was exercised especially by the director of another reference of the genre, formally situated at the opposite extreme: Claude Lanzmann, the director of the monumental Shoah. Now, a quarter of a century later, we analyze in this article what remains of the discussion and of Spielberg's model of narration of what was one of the bleakest episodes of recent history: the nazi attempt of the Jews' extermination.

La lista di Schindler rappresenta un punto di svolta nella narrativa dell'Olocausto. Sebbene sia stato ben accolto dalla critica e dal pubblico, cosa insolita nella carriera di Steven Spielberg, considerato un autore per bambini e abbastanza bravo solo come regista di avventure, il film non è stato accettato in maniera altrettanto positiva dagli intellettuali ebrei. La critica negativa alla crudele ma speranzosa favola di Spielberg è stata esercitata soprattutto dal regista di un altro riferimento del genere, situato formalmente nell'estremo opposto: Claude Lanzmann e la sua monumentale Shoah. Ora, un quarto di secolo più tardi, analizziamo in questo articolo ciò che resta della discussione e del modello di Spielberg della narrazione di uno degli episodi più neri della storia recente: il tentativo nazista di sterminio degli ebrei.

\section{Palabras clave / Mots-clé I Key words / Parole chiave}

Holocausto, shoah, nazi, Schindler, memoria, Spielberg.

Holocaust, shoah, nazi, Schindler, memoire, Spielberg.

Holocaust, shoah, nazi, Schindler, memory, Spielberg.

Holocaust, shoah, nazisti, Schindler, memoria, Spielberg. 


\section{Introducción}

El Holocausto judío ha gozado de una abundante representación tanto literaria como audiovisual a lo largo de la historia aunque, como enseguida veremos en detalle, no fue así desde el principio. Ya en 1983, Annette Insdorf contabilizaba más de 200 filmes sobre la denominada por los nazis «Solución Final»: el exterminio sistemático y organizado del pueblo judío que se produjo en los años 30/40 en buena parte de Centroeuropa (Rees, 2005). En diciembre de 1993, hace algo más de un cuarto de siglo, se estrenaba la película de Steven Spielberg que en ese momento dio un bandazo, uno más, a la carrera del director. Una película sobre los judíos, rodada en blanco y negro, con un tema muy alejado de los que hasta el momento había tratado un director considerado como de acción y aventuras, y en ocasiones incluso infantil: La lista de Schindler (Schindler's list, 1993).

El film tuvo a pesar de su temática un éxito inmediato, tanto de crítica - al menos la mainstream - como de público. No en vano es considerada como un cuento de hadas: incluso durante el Holocausto, algunos de los chicos malos devienen en chicos buenos (Gourevitch, 1994). La lista ganó siete premios Óscar, entre ellos el de mejor película y mejor director, pero no todo fueron alabanzas. Según David Mamet, Spielberg transformó el sufrimiento de los judíos en pornografía emocional (en Picart y Frank, 2006). El modelo de representación fue criticado precisamente por esto. En el universo de la Shoah y sus acompañamientos abundan los defensores del dogma. Uno de los más destacados, fue el reconocido documentalista Claude Lanzmann que dirigió un durísimo testimonio de la barbarie nazi en Shoah (1985), con un metraje de 566 minutos en el que renuncia además por completo a la utilización de imágenes de archivo o banda musical. Más allá de su propuesta estética situada en las antípodas del cine de Spielberg, Lanzmann se erigió en defensor de la pureza obligada en aquellos relatos relacionados con el horror nazi. A partir del éxito de La lista de Schindler y más allá de la polémica, la reivindicación de la memoria de los judíos experimentó un revival considerable.

Entre los autores judíos que han dedicado su vida a reflexionar y estudiar sobre la Shoah hay una idea bastante generalizada sobre la imposibilidad o al menos la dificultad que entraña su representatividad. Según Hannah Arendt, no hay nada más difícil de contar en toda la historia de la humanidad (2005). Para Theodor Adorno es inaceptable obtener placer estético o lector de una obra de arte que trate el Holocausto y Elie Wiesel afirmó que Holocausto e inspiración literaria eran una contradicción terminológica (en Vice, 2000). También Arendt decía que sobre la lección de la terrible banalidad del mal, «ante la que las palabras y el pensamiento se sienten impotentes» (1963: 98). Las cifras de la masacre organizada y sistemática son sin duda sorprendentes: provocó la desaparición de entre 5 y 6 millones de judíos, pero también como destaca Bensoussan, en esos asesinatos estuvieron implicados de manera directa un millón de personas que colaboraron con el régimen de los nazis y sin las cuales no habría sido posible el Holocausto (2005). El antisemitismo en Europa se remonta según este autor al siglo XI cuando durante los primeros ataques ya se les hacía llevar una prenda distintiva de color amarillo en 1215. Lo que hace el partido nazi es martillear con una propaganda vieja en el fondo y moderna en la forma (Bensoussan, 2005; Rees, 2017).

Lo cierto es que la representación y la forma de afrontarla tiene consecuencias políticas: cómo imaginamos un hecho, determina nuestra visión del mundo y cómo lo interpretamos (Picart y Frank, 2006). Hay que reconocer la puesta en marcha de una maquinaria de pseudohistorización que se desarrolla para influenciar el gran público y su memoria colectiva, y que funciona en paralelo y sustituyendo a los avances en la investigación histórica (Sánchez Biosca, 2006). Claude Lanzmann se alinea con los que defienden el carácter incomparable o único del exterminio. Incluso explicita un rechazo a entender lo que piensa el asesino, ya que considera que es el primer paso para justificar el crimen (Sánchez Biosca, 2006). 
Unos pocos años después del estreno de la propuesta narrativa de Lanzmann, llegó La lista de Schindler, resultando un enorme éxito comercial que la convirtió en el candidato perfecto para ocupar el espacio en las antípodas de Shoah. Según autores como Hofmann, el principal problema de la película que retrata al personaje real de Oskar Schindler es que el horror del Holocausto pasa a ocupar un segundo plano, al quedar eclipsado por el tema de la salvación de los judíos, lo que casa con la necesidad de armonía y la reconciliación. Para ello el director utiliza recursos emocionales y estéticos que explican su éxito comercial. Sin embargo en el contexto real de la Shoah, el principio de armonía tendría que ser sistemáticamente cuestionado ante biografías de antiguos ocupantes de los campos como la de Elie Wiesel y Primo Levi (2011).

\section{Objetivos y metodología}

Veinticinco años largos después del estreno de La lista de Schindler, y cerca de ochenta transcurridos desde que pasaron los hechos, queremos en este artículo ver de qué manera el Holocausto se mantiene -o no- como un tema recurrente en la narración audiovisual desde una perspectiva contemporánea, y comprobar cómo ha evolucionado durante estos últimos años la discusión respecto a las formas de representación adecuadas para narrar este episodio de la historia. La hipótesis de partida es que el film de Spielberg se ha integrado con éxito, después del tiempo transcurrido, en el relato general sobre la Shoah, a pesar de las durísimas críticas iniciales por parte de la crítica “oficial”, de las voces autorizadas del judaísmo. El éxito sin precedentes de la propuesta audiovisual, la ha convertido en modelo inexcusable posterior, y ha contribuido además a mantener el Holocausto en la agenda, conservando una salud excelente sin que se perciba en absoluto cansancio ni saturación, al menos aparente, sobre la cuestión del exterminio judío.

Para realizar el estudio, hemos realizado una metodología de análisis fílmico desde el punto de vista tanto del contenido como del aspecto formal, así como de las decisiones narrativas especialmente sensibles, por el carácter referencial de las imágenes inherentes al relato cinematográfico -documental o no- a la hora de contar lo que ha sido definido como inefable, tal como veremos.

\section{El olvido inicial y la lenta recuperación de la memoria}

Durante la liberación que se produjo entre 1944 y 1945 , las tropas aliadas, formadas por soviéticos, americanos y británicos, fueron accediendo según avanzaban a los distintos campos de concentración y exterminio. El General George S. Patton parece ser quien decidió, vistos los horrores de esos espacios, que las cámaras dejaran constancia para la historia. Entre los camarógrafos y directores que acompañaban las tropas norteamericanas, hubo algunos de los grandes nombres del cine de Hollywood como John Ford, Samuel Fuller y George Stevens. Fue este último en solitario el que firmó como director una de las obras que retrataron la represión nazi tal como la vieron los primeros soldados aliados que accedieron a los campos. Campos de concentración nazis (Nazi concentration camps, George Stevens, 1945) fue presentado como evidencia en los juicios de Núremberg, y quedó fijado como referencia audiovisual más inmediata del Holocausto. Sin ningún tipo de filtro, la película muestra las fosas abiertas, las cámaras de gas, los hornos crematorios, las pilas de gafas de las víctimas, los cuerpos de los muertos, la imagen descarnada de los supervivientes. Todo un ejercicio del gore más real al servicio de la denuncia ejercitada, eso sí, por los militares: no en vano el director, firma la película como Teniente Coronel Stevens. Cabe destacar en cualquier caso, el carácter metonímico de las imágenes: en ninguna de ellas se muestran los crímenes, sino tan sólo sus consecuencias (Sánchez Biosca, 2006)

Si algo llama la atención clamorosamente en un visionado actual es la ausencia de referencias a las víctimas judías. Después de diversas enumeraciones repetitivas en un largo recorrido por los sucesivos campos de exterminio que visitaron los servicios de propaganda es- 
tadounidenses, tan sólo en una ocasión el locutor dice, y de pasada, que entre los gaseados había judíos. Poco, muy poco, sobre todo cuando conocemos las cifras comparativas: el 90\% de los muertos en los campos de exterminio fueron judíos (Longerich, 2010). También cuando los reporteros de la BBC entran en el campo de Bergen-Nelsen, liberado en abril de 1945, a pesar de que entre 40 y 60 mil de los detenidos son judíos, en las crónicas no hacen la menor alusión a ello. No interpreta Bensoussan en esto un antisemitismo larvado o pasivo, sino imposibilidad de abarcar una realidad cruel (2005).

Otro caso fue el de German Concentration Camps Factual Survey, (Sydney Bernstein, 2014) el equivalente británico a la película de Stevens en el que tampoco faltaron colaboradores de prestigio -el propio Alfred Hitchcock actuó como consejero-. El gobierno decidió censurarlo, y fue una iniciativa del Imperial War Museum la que finalmente consiguió que se estrenara después de restaurar los negativos y montarlo de nuevo de acuerdo al guion original. Fue casi setenta años después. Tampoco los británicos consideraron necesario mencionar a las víctimas judías en esta película de denuncia (Lena, 2019). Estos casos son sintomáticos del ocultamiento -premeditado o no- que el Holocausto sufrió los primeros años. Al principio, se evitó la confrontación para no relacionarla con el intento de aniquilación del pueblo judío e incluso los juicios de Núremberg pasaron desapercibidos cuando se celebraron en una Alemania que estaba más preocupada por la reconstrucción física que por la moral (Aizenberg, 2016). Es significativo que la versión cinematográfica hollywoodiense sobre los juicios, Vencedores o vencidos (Judgment at Nuremberg, Stanley Kramer, 1961) se hizo esperar unos cuantos lustros. Sin duda el cine estadounidense evitó analizar el problema de la responsabilidad colectiva del pueblo alemán frente al Holocausto especialmente en los primeros tiempos (Mintz, 2001). Tan sólo la mirada lúcida de Orson Welles, en El extraño (The stranger, 1946), puso el dedo en la llaga con un retrato de esa clase alta norteamericana que prefirió mirar al otro lado durante la guerra, y señaló hacia los miles de nazis que se repartirían impunemente por el mundo sin responder por sus crímenes.
La representación de la víctima judía experimentó una evolución, «desde su intrascendencia inicial, hasta su estatuto de víctima ejemplar» (Lozano Aguilar, 2015), y el modelo sobre el Holocausto que resultaría de larga duración se inició con una película precisamente dirigida por George Stevens, Diario de Ana Frank (Diary of Anne Frank, 1959) basada en el libro memorialístico previo y éxito superventas. Alan Mintz (2001) destaca también como eventos cruciales para esa recuperación del Holocausto el juicio de Eichmann en Jerusalén, La guerra de los Seis Días, la fundación del norteamericano Memorial Holocaust Museum y la miniserie de televisión Holocausto (Holocaust, Marvin J. Chomsky, NBC, 1978)

$\mathrm{El}$ juicio de Adolf Eichmann, -considerado responsable directo de la «solución final»- se convirtió quince años después del fin de la guerra, en un símbolo de la justicia sionista que llega inexorable, aunque tarde. Su detención en Argentina por agentes del Mossad-los servicios secretos israelíes- y su juicio público y posterior ejecución en la Israel de Ben Gurión, tuvo un impacto considerable en la opinión pública a nivel mundial. De las reflexiones de Hannah Arendt sobre este juicio, nos queda la muy extendida lección sobre la banalidad del mal (1963). Lo grave fue advertir que Eichmann no era un sádico pervertido y que hubo muchos hombres como él. Estos hombres fueron, y siguieron siendo en muchos casos después de la guerra, terrible y terroríficamente mortales. El nazi organizador de los convoyes hacia los campos de exterminio reconoció también que la colaboración de los Judenrat-asambleas de judíos en los guetos- constituía la piedra angular de su trabajo de recopilación y limpieza, y estos dirigentes casi sin excepción colaboraron con los nazis de un modo u otro, por una u otra razón (Arendt, 2005). Sin esa ayuda por parte de los propios judíos, difícilmente las víctimas hubieran llegado a la tremenda cifra de entre 5 y 6 millones. Cabe recordar que el $99 \%$ de los judíos deportados a campos en Holanda, fallecieron. Los que se ocultaron por un medio u otro - como hizo la familia de la misma Anna Frank-sobrevivieron cerca del 50\%.

Estas nuevas ideas alejadas de la visión monolítica y maniquea de personajes sin matices a ambos lados 
de la balanza del mal enriquecerán, en algunos casos, la reflexión y la narrativa posterior sobre el Holocausto.

\section{Spielberg y la Shoah de Lanzmann}

La película de Spielberg adapta la ya exitosa novela biográfica del australiano Thomas Keneally El arca de Schindler (Shindler's Ark, 1982) que retrata las vivencias de un empresario que salvó a más de mil judíos polacos empleándolos en sus fábricas durante la Segunda Guerra Mundial. Es un personaje ambivalente, que en el libro queda retratado de forma mucho más oscura: su propia mujer declara que realmente no hizo nada excepcional ni antes de la guerra ni después. De hecho, fue un afortunado que entre 1939 y 1945, encontró gente que convocó sus talentos ocultos (Keneally, 1982). En la novela se narra cómo su vida estuvo marcada por el alcoholismo, la bancarrota y los problemas financieros que sufrió permanentemente, y que cuando fue homenajeado por Yad Vashem, esto le produjo problemas y ataques en Alemania (Gourevitch, 1994).

Spielberg utilizó estos mimbres adaptándolos por un lado a las convenciones del melodrama, y por otro a la tradición de los films de horror clásicos de Hollywood (Picart y Frank, 2006). Dentro de la filmografía del autor de E.T. el extraterrestre (E.T. the extra-terrestrial, 1982) y de Parque Jurásico (Jurassic Park, 1993), significó un punto de inflexión, una madurez repentina del autor que además asumió su substrato cultural judío hasta entonces obviado. Eso sí, cabe recordar que Spielberg y su universo infantil no es sencillo ni feliz. Sus entornos reflejan estrés, caos y vidas solitarias (Friedman, 2006). El llamado «Rey Midas de Hollywood»-aunque no siempre sus películas han resultado un éxito (LópezOlano, 2001) - se atrevió con un film con un argumento durísimo, a pesar de sus condicionantes, y rodada casi íntegramente en blanco y negro. Dicen que las películas son un medio en el que cuanto más éxito tienes comercialmente, menos aceptable eres en la comunidad de críticos, al menos hasta que estás muerto, ponien- do como ejemplo a Hitchcock (Marchel en Friedman, 2006). Esto ocurría sin duda con Spielberg, pero con La lista de Schindler se reconcilió con buena parte de la crítica y la Academia de Cine y por primera vez obtuvo el Óscar a mejor director.

El film retrata, sin lugar a dudas, a los judíos como infantilizados, pero más allá de Schindler, el auténtico héroe de la película es Itzhak Stern: él encuentra los mecanismos necesarios para salvar a su gente. Pero eso sí, sin el profesional del marketing y de las relaciones públicas que es el miembro del Partido Nazi, la empresa no podría tener éxito. Podemos destacar dos escenas principalmente en el melodrama spielbergiano: La primera, la de la ducha, en la que se nos muestra como un grupo de judías entra en lo que nos parece -también a ellas- una cámara de gas. Finalmente, se trata tan sólo de una ducha real, en la que tanto presas como espectadores reciben el agua con regocijo. Se ha relacionado el juego cinematográfico con la mirada y el terror en esta secuencia con la clásica de la ducha en Psicosis de Alfred Hitchcock (Psycho, 1960) (Picart y Frank, 2006). A pesar de que algún autor ha destacado que la novela está desplazada ya varios pasos de la veracidad absoluta y de que el film entra ya en otra categoría totalmente distinta a la de la representación de la realidad (Franklin, 2011), lo cierto es que la anécdota de la ducha/cámara de gas ocurrió realmente y está narrada por testimonios directos en el libro de Keneally.

La segunda secuencia destacable es la de la Aktion de Cracovia, en la que aparece casi el único punto de color en la película: el abrigo rojo de la niña que avanza por medio de la calle en la que los nazis están asesinando impunemente y de día a los vecinos del gueto. La escena es definida por Friedman (2006) como la piedra angular de la filmografía de Spielberg, narrada desde el punto de vista de Schindler, que observa la acción subido a un caballo desde un promontorio cercano. También Gourevitch (1994) considera que es el desencadenante de la premonición del protagonista que percibe ya claramente que el objetivo de los nazis es la aniquilación absoluta del pueblo judío. La visión del empresario nazi deviene la del director. Lo que vemos a través suyo es lo 
que ocurre en ese plano inferior del gueto, la crueldad sin límite de los represores, la anécdota de los soldados que alinean a sus víctimas para ahorrar en balas al dispararles. También el sinsentido de esa niña que Schindler sigue con la mirada y que parece evitar al menos momentáneamente su destino mortal dotando de esperanza la escena. Simboliza la humanidad, la salvación aún posible si al menos esa niña puede librarse de la aniquilación. La veremos siempre desde la perspectiva del miembro del partido nazi que está a punto de redimirse. A partir de ese momento, decide que va a dedicar su vida a salvar a todos los judíos que pueda, y Spielberg, que lo narrará para que nadie lo olvide. Aquí sí que el director va más allá que la novela en la que se basa, la biografía de Keneally, que en ningún momento da una explicación clara de los motivos de Schindler para hacer lo que hizo (Vice, 2000).

Indudablemente, el éxito rotundo de La lista de Schindler provocó una catarata tanto de films como de novelas que se prolonga hasta nuestros días. Más allá de esa nueva lista, la concienciación de Spielberg como descendiente de judíos ashkenazis hizo que a partir de ese momento reivindique activamente el recuerdo del Holocausto, e incluso que financie y dirija activamente iniciativas como la University of South California (USC) Shoab Foundation Institute for Visual History and Education ${ }^{1}$ con el objetivo de grabar y conservar testimonios del terror nazi convirtiéndose pronto en una de las bibliotecas de video digital más grandes del mundo. Con acceso y difusión a través de la web, esta iniciativa propone actividades docentes y campañas en redes sociales para conservar viva la memoria.

Frente a este modelo de representación melodramático, impactante anímicamente, pero dejando espacio para la esperanza, se alza otro de muy distinto calado y que se formalizó como obra audiovisual con el singular ya citado documental Shoah. Sin música, sin imágenes de archivo, sin concesiones. Claude Lanzmann ni siquiera concibió su troceamiento, para que se adaptara su metraje de nueve horas y media a los usos y costum-

https://sfi.usc.edu [consulta: 15/07/2019] bres del consumo audiovisual. Aun así, después de su estreno en el año 1985 consiguió convertirse en referencia obligada dentro de la corriente de recuperación del Holocausto -ya muy boyante- que existía en ese momento. Cabe decir que la obra de Lanzmann es casi única, ya que su filmografía se reduce a tan sólo media docena de títulos, todos con el mismo tema. La película consiguió de inmediato una repercusión muy importante, y su aparición provocó que el canon del horror de la Shoah sufriera un giro sin precedentes (Lozano, 2015).

Como opción explícita, el director que trabajó durante once años con exclusividad en la película, renuncia al uso de imágenes de archivo: no es necesario, su camino es claramente otro. «Su pedagogía de la imagen está basada en la puesta en movimiento de la imaginación del espectador, con una puesta en escena que muestra el testimonio como un actor y autor, filmando la Shoah en presente» (Torner, 2005: 52). Eso sí, Lanzmann no tiene ningún problema moral en enfrentarse con una víctima, en presionarla hasta que recuerde y enuncie en voz alta, por el bien de su Shoah, que un compañero cortó el pelo a su mujer y su hija, antes de verlas entrar en la cámara de gas. Es la declaración de Abraham Bomba, el peluquero de Treblinka, y se trata de uno de los fragmentos más duros de toda la película, de los que con su emotividad compensan el metraje excesivamente largo y lento. Sus entrevistados se convierten en tan sólo actores, aunque Lanzmann critica duramente la representación explícita de las cámaras de gas que hace Spielberg (Torner, 2005).

A partir del estreno, el director se convierte en privilegiado analizador de su propia obra, y guardián de las esencias de los relatos sobre la aniquilación de los judíos (2005). El autor cargó inmisericorde en Le Monde y en Globe Hebdo contra Spielberg, acusándolo de trivializar el espectáculo. Pero también lo hizo contra el Korçak de Andrej Wajda (1990) donde también en un blanco y negro radiante, el polaco retrataba otro héroe asesinado en Treblinka junto a los niños del orfanato que dirigía. El origen de este recurso como convención del pasado aplicada al Holocausto lo podemos encontrar también en el cortometraje documental Noche y Nie- 
bla (Nuit el Brouillard, Resnais, 1955) (Sánchez Biosca, 2006). Lanzmann también cargó duramente contra Roberto Benigni por su singular La vida es bella (La vita è bella, 1997), en la que da una vuelta de tuerca completa al relato del Holocausto al incorporar al humor, sin dejar de ser una obra de denuncia. No en vano, Benigni es un potente heredero de la Commedia dell'arte y del cómico italiano Totó. Con su película, las atrocidades y el sufrimiento de los judíos adquieren una dimensión trágica nueva (Bracco, 2019). La combinación de humor y denuncia del régimen nazi tampoco era nueva: es lo que Insdorf (1983) denomina «el toque irónico» y que podemos encontrar en obras maestras como El gran dictador (The great dictator, Charles Chaplin, 1940) o en Ser o no ser (To be or not to be, Ernst Lubitsch, 1942). Incluso el cómico Jerry Lewis intentó abordar la mezcla previamente en la película maldita The day the clown cried (1972). Después de las críticas iniciales, quedó sin estreno oficial e inacabada.

Es curioso que hasta en los libros dedicados a glorificar la visión purista de la narración sobre la Shoah de Lanzmann, se acaba por hablar primero del modelo opuesto, el que representa Steven Spielberg, como ocurre por ejemplo en el texto de Carles Torner (2005). En cualquier caso, ante esta concepción dicotómica sobre la cuestión judía, La lista de Schindler está claro que no desplaza otros films ni sustituye otras narrativas sobre el Holocausto, ni siquiera elimina la necesidad de estudiar la historia (Friedman, 2006).

\section{El holocausto ahora}

Desde el revival experimentado después del estreno del film de Spielberg, el interés por el Holocausto no ha decaído hasta ahora, ni en el audiovisual, ni en la literatura. Las biografías/testimonio han seguido siendo uno de los subgéneros con más éxito, con obras como El pianista (The Pianist, 2002) donde también otro judío ashkenazi con éxito en Hollywood, Roman Polanski, adapta unas memorias de un personaje real. Incluso el cine español ha tratado el tema, con El fotógrafo de Matthausen (Mar Tar- garona, 2018) basada en la historia de Francesc Boix, el único español que declaró en los juicios de Nuremberg. Las adaptaciones al cine de libros de éxito han sido continuas: El niño con el pijama de rayas (The boy in the striped Pyjamas, Mark Herman, 2008), en 2016 llegó la enésima adaptación del clásico libro de Ana Frank, en esta ocasión en versión alemana, con Das tagebuch der Anne Frank (Hans Steinbicher). Kate Winslet obtuvo el Óscar con El lector (The reader, Stephen Dauldry, 2008), adaptación de la novela homónima de Bernhard Schlink (1995).

La lista es inabarcable, buena prueba de ello es hacer constar tan sólo las novelas que combinan en su título un oficio y el nombre de un campo de exterminio: $L a$ bibliotecaria de Auschwitz. (Antonio G. Iturbe, 2012), El violín de Auschwitr (Maria Àngels Anglada, 1997), o El Tatuador de Auschwitz. (Heather Morris, 2018). El éxito de ésta última -las memorias de un judío superviviente del campo de exterminio traducidas a 43 idiomasprueba que el tema no muestra signos de agotamiento. El documental australiano El contable de Auschwitz. (The accountant of Auschwitz, Matthew Shoychet, 2018) ha probado muy recientemente que se puede tratar de nuevo el tema y hacerlo de manera original. Esta producción pone el dedo en la llaga, recordando la culpabilidad de cientos de miles de personas que apoyaron el nazismo y quedaron impunes, y la poca implicación inicial del pueblo alemán en los procesos de Núremberg, que fueron vistos como la venganza de los vencedores más que como un acto de justicia. Esta cinta utiliza las fotos, las imágenes consabidas de la apertura de los campos grabada por las tropas de liberación, lleva también a los testigos a la geografía del horror, recoge la visión de los expertos y los negacionistas, y también muestra el punto de vista de Oskar Grönig, el ex miembro de las SS juzgado por crímenes de guerra poco antes de morir que protagoniza la historia. Recuerda también este film lo que remarcaba George Bensoussan: los soldados alemanes que se negaron a participar en las ejecuciones, no fueron en general sancionados, más allá de algún caso singular (2005).

También en la oscarizada película húngara de ficción El hijo de Saúl (Saul fia, Laszlo Nemes, 2015) vemos re- 
tratado Auschwitz. Y lo vemos tal como lo aprecia un miembro de un Sonderkommando, las brigadas de judíos encargados de quemar los cadáveres de sus compañeros gaseados, entrando dentro de las cámaras, de los hornos crematorios, mostrando la degradación extrema de las fábricas de matar. Tal como dijo un crítico: «El Holocausto como nunca lo habíamos visto antes» (Marañón, 2016).

Buena prueba de la salud del subgénero la podemos encontrar haciendo una búsqueda en el catálogo de $\mathrm{HBO}$ o Netflix. En ésta última plataforma, al cierre de este artículo, encontramos una veintena de películas y series, por ejemplo, el citado Campos de concentración nazis, también una serie documental sobre los Einsatzgruppen -los escuadrones de la muerte nazis- así como las producciones propias de Netflix, El banquero de la resistencia (Banker van her verzet, Joram Lürsen, 2018) y Operation Finale (Chris Weitz, 2018). En esta última, una superproducción con los actores Oscar Isaak y Ben Kingsley como protagonistas, se narra la controvertida operación de secuestro por el Mossad en Argentina y el posterior juicio en Jerusalén al que se enfrentó el jerarca nazi Adolf Eichmann.

En España, nuestros condicionantes históricos como país que sufrió su propia represión brutal por motivos ideológicos ha marcado una relación con la memoria histórica que está ahora mismo en plena ebullición y con aún numerosas asignaturas pendientes (López-Olano, 2019). En nuestro contexto inmediato se produjo un vendaval de sangre, con ejecuciones en la postguerra no por delitos concretos, sino por pura represalia política. «El fusilamiento después de la parafernalia del juicio sumarísimo, por sus especiales características de violencia, sonoridad y por qué no decirlo, vistosidad fue una de las bases de la implacable máquina represora del incipiente nuevo estado» (Gabarda, 2011: 19). Un millón de españoles acabaron en los campos de concentración franquistas, 200.000 son las víctimas estimadas durante la represión de la postguerra, y hay constancia de que expertos venidos de Alemania asesoraron a los responsables de la España franquista. Hay que huir de las comparaciones, fáciles, con los campos alemanes, pero no por ello minimizar nuestras víctimas (Hernández, 2019). La recuperación de la memoria tarda, aunque a veces demasiado. El juicio del genocida camboyano Kaing Guek Eav (Duch), que como Eichmann alegó obediencia debida (Sánchez Biosca, 2017) llegó 30 años después del fin del régimen de los Jemeres Rojos.

Recientemente se ha producido en el panorama audiovisual una emergencia de la representación de la historia reciente de España, con series como Amar en tiempos revueltos (Josep Maria Benet, Antonio Onetti y Rodolf Sirera, Diagonal TV, 2005-2012), 23-F: el dia más difícil del rey (Silvia Quer, Alea Docs \& films, 2009) y La chica de ayer (Álvaro Ron et al., Ida y vuelta, 2009). También en cine Silencio roto (Montxo Armendáriz, 2001), El laberinto del fauno (Guillermo del Toro, 2006) y Las trece rosas (Emilio Martínez Lázaro, 2007) o Los girasoles ciegos (José Luis Cuerda, 2008) (Palacio y Ciller, 2010). En 2018 se estrenó también la ya citada, ésta sí sobre un testigo y protagonista del Holocausto El fotógrafo de Matthausen. Estos ejemplos de nuestro cine compensan ahora la sobreexplotación audiovisual de los referentes bélicos clásicos norteamericanos como la guerra de Secesión, la Segunda Guerra Mundial o la de Vietnam, mientras que nuestras guerras y víctimas son aún una asignatura pendiente (Chicharro y Rueda, 2008).

Más allá de todos estos ejemplos actuales de películas y documentales sobre el Holocausto, la influencia llega incluso más lejos. El cuento de la criada (The handmaid's tale, Bruce Miller, Hulu, 2017-2019), la serie de fantasía distópica basada -al menos en sus inicios- en el cuento de Margaret Atwood, con ese régimen imaginario de la República de Gilead instaurada en Estados Unidos, tiene mucho que ver con los nazis, su sistema represivo y con una estética formalizada desde hace décadas. Las castas, en este caso determinadas por el sexo o por la desviación sexual, o por la falta de adscripción al régimen, portan uniformes, con colores clave, que determinan su ubicación dentro de la estratificada estructura social de Gilead. En esa dictadura jerárquica de fanáticos los disidentes son enviados a unas colonias que semejan campos de concentración. La estética basada en el uso de colores clave: el negro para los jerarcas, el 
verde azulado para las esposas, el rojo para las criadas/ engendradoras hace que en ocasiones se produzcan rimas con el juego de oposición entre el blanco y negro matizado por el detalle de la niña en rojo que hemos comentado en La lista de Schindler. También la compleja relación de dominación sádica y cruel del Comandante Fred Waterford -Joseph Fiennes- con June Osborne Elisabeth Moss- recuerda la del comandante del campo de concentración Amon Göth -interpretado por Ralph Fiennes, quizás no casualmente hermano del anterior y con un gran parecido físico- con su criada judía. El cambio está aquí en que la antagonista femenina en la película de Spielberg mostraba una angustiante pasividad, mientras que en la serie la criada protagonista -ya no víctima como integrante de una raza/cultura/religión, sino del sexo femenino- es una superviviente activa e inteligente, que sólo muestra mansedumbre para poder obtener poder en su particular cruzada para recuperar a su hija. La serie es conocida por sus efectos visuales y por la crueldad extrema contra las mujeres que mostraba explícitamente desde sus primeros capítulos, lo que le valió algunas críticas que no consiguieron oscurecer su éxito. Las citas explícitas a Spielberg se suceden, como cuando June en el capítulo diez de la tercera temporada, después de recibir cientos de magdalenas de las Marthas que confirman su colaboración en la gran operación de liberación de los niños robados, dice la recordada frase de Tiburón (Jaws, Steven Spielberg, 1975) «Necesitaremos un barco más grande».

\section{Conclusiones}

La primera y más clara conclusión es la buena salud actual de la temática del Holocausto. Para ello partimos del hecho evidente de la negación y ocultamiento que sufrió la cuestión judía en los primeros años después de que los nazis perdieran la guerra. Ahora más de 70 años después de las atrocidades aparejadas al plan sistemático exterminio, tanto en cine como en literatura no se aprecia signo de recalentamiento en la recuperación de la memoria de ese genocidio contra los judíos. Todo esto, un cuarto de siglo después del estreno de un film, La lista de Schindler, que se convirtió en modelo y referencia de muchas otras propuestas estéticas que se han hecho en todo este tiempo.

La dicotomía clásica de la narrativa de la Shoab se plantea entre en primer lugar, los puristas partidarios de la no representación, como hemos visto respaldada por prestigiosos teóricos y filósofos judíos y que cristaliza en la película de Claude Lanzmann, él mismo un teórico; y en segundo lugar, por los partidarios de la utilización de cualquiera de los recursos cinematográficos y narrativos al alcance del director en aras de conseguir el objetivo comunicativo, cuyo ejemplo máximo encontramos en el film de Spielberg. Es al final, una diferenciación formal: la distancia entre la sutilidad de la no mostración, de la sugerencia, y en el otro extremo el de la explicitación en el uso de todo lo que sea necesario, de todos los mecanismos por ejemplo los habituales en el melodrama clásico. Al fin y al cabo, la emoción existe y llega también, aunque con técnicas diferentes, al visualizar al lanzmanniano peluquero de Treblinka con sus largos silencios y miradas al vacío, cómo confiesa que uno de sus compañeros cortó el pelo a su mujer y sus hijos antes de que fueran introducidos en la cámara de gas. Sin duda con la recuperación de esa historia brutal cualquier otro recurso, está de sobra.

En la narrativa actual, en cualquier caso, parece bastante claro que es la propuesta de Spielberg la que ha triunfado en esa guerra por la narrativa del Holocausto. Incluso películas muy alejadas del lirismo y discurso esperanzado de La lista de Schindler, como El hijo de Saúl, descarnada e incómoda, utilizan sin ningún tipo de remordimiento todas las imágenes que se creen necesarias para retratar la terrible historia. También el aclamado El contable de Auschwitz a pesar de su carácter documental y reacio a la emoción emplea imágenes de archivo y fotos que muestran la barbarie nazi para ilustrar sus tesis. Por otra parte, hemos visto como la estética y los personajes de La lista de Schindler contaminan incluso propuestas audiovisuales que no narran directamente acontecimientos relacionados con el Holocausto, como en El cuento de la criada. La herencia de Spielberg sigue muy viva. 


\section{Bibliografía}

Aizenberg, E. On the Edge of the Holocaust. Waltham, Massachusetts: Brandeis University Press, 2016.

Arendt, H. Eichmann in Jerusalem. A Report on the Banality of Evil. New York: Viking Press, 1963.

Arendt, H. Ensayos de comprensión 1930-1954: Escritos no reunidos e inéditos de Hannah Arendt. Madrid: Caparrós, 2005. Bensoussan, G. Historia de la shoah. Barcelona: Anthropos, 2005.

Bracco, D. Bufonadas y monstruosidades: Una retórica del exceso en el cine cómico de Roberto Benigni. L'Atalante. Revista de estudios cinematográficos, $O$ (27), 2019 Recuperado de http://links.uv.es/vM2i8Dk

Franklin, R. A thousand darknesses. Oxford [u.a.]: Oxford Univ. Press, 2011. Recuperado de http://links.uv.es/ pUym7Me

Friedman, L. D. Citizen Spielberg. University of Illinois Press, 2006. Recuperado de http://links.uv.es/ $\mathrm{sP} 1 \mathrm{H} 7 \mathrm{vm}$

Gabarda, V. Els afusellaments al País Valencià (1938-1956). València: Publicacions de la Universitat de València, 2011.

Gourevitch, P. «A dissent on "Schindler's list"». Commentary, 97, (49), 1994.

Hernández, C. Los campos de concentración de Franco. Barcelona: Ediciones B, 2019.

Hofmann, M. Historia de la literatura de la Shoah. Rubí, Barcelona: Anthropos Editorial, 2011.

Insdorf, A. Indelible Shadows. New York, NY: Vintage Books, 1983.

Keneally, T. Schindler's Ark. London: Hodder Stoughton, 1982.

Lena Ordoñez, A. (2019). Víctimas y verdugos: La representación de Alemania en el cine clásico de Hollywood, 1942-1954. L'Atalante. Revista de estudios cinematográficos, $O$ (27), 2019. Recuperado de http:/ /links. uv.es/oHU0JQJ

Longerich, P. Holocaust: The Nazi Persecution and Murder of the Jews. Oxford; New York: Oxford University Press, 2010.
López-Olano, C. «Memoria y Universidad: una experiencia transmedia». En: Contenidos y formatos transmedia para la comunicación universitaria. (coord Miquel Francés y Guillermo Orozco Madrid: Síntesis (en prensa)

López-Olano, C. Guía para ver y analizar: En busca del arca perdida. Steven Spielberg (1981). Valencia: Nau Llibres, 2001.

Lozano Aguilar, A. (2015). Victimas y verdugos en Shoah (Claude Lanzmann, 1985). Genealogía y análisis de un estado de la memoria del Holocausto. Tesis doctoral, 2015. Valencia: Universitat de València. Recuperado de http://links.uv.es/qx0L341

Marañón, Carlos. El bijo de Saúl (crítica). Cinemania, (Enero), 2016. Recuperado de https:// cinemania.20minutos.es/peliculas/el-hijo-de-saul/ critica/

Mintz, A. L. (2001). Popular Culture and the Shaping of Holocaust Memory in America. Seattle: Univ. of Washington Press, 2001.

Palacio, J. M., \& Ciller, M. C. «La mirada televisiva al pasado. el caso español (2005-2010)». En J. C. Ibánez, \& F. Anania (Eds.), Memoria histórica e identidad en cine y televisión. Madrid: Contextos, 2001.

Picart, C. J., \& Frank, D. A. Frames of Evil. Carbondale: Southern Illinois Univ. Press, 2006.

Rees, L. Auschwitz. Los nazis y la "Solución Final". Barcelona: Crítica, 2005

- El oscuro carisma de Hitler. Barcelona: Crítica, 2017.

Sánchez Biosca, V. «Imágenes marcadas a fuego: Representación y memoria de la Shoah». Revista Brasileira de História, 21 (42), 2001, 283-302. doi: 10.1590/ S0102-01882001000300002

- Cine de historia, cine de memoria: La representación y sus limites. Madrid: Catedra, 2006.

- Miradas criminales, ojos de víctima. imágenes de la aflicción en Camboya. Buenos Aires: Prometeo, 2017.

Torner, C. Shoah: Cavar con la mirada. Barcelona: Gedisa, 2005.

Vice, S. Holocaust Fiction. London: Routledge, 2000. 